\title{
Multiple tracheal stenting or perseverare diabolicum est
}

\author{
Matthias Altmayer, MD, ${ }^{a}$ Christian Biancosino, MD, ${ }^{a}$ Jochen Strauss, MD, ${ }^{b}$ and Paolo Macchiarini, MD, PhD, \\ Hannover and Berlin, Germany
}

$\mathrm{M}$ ost would agree that a flexible application of a variety of endoscopic techniques, even combined in the same patient, provide the best chance for a successful outcome for benign but unresectable airway obstruction. ${ }^{1}$ However, concern has been raised concerning the enthusiastic attitude toward endoluminal stents and their preference over surgical repair in the absence of true contraindications. $^{2}$ A life-threatening clinical scenario of this attitude is presented here.

\section{Clinical Summary}

A 38-year-old man was referred mechanically ventilated and nasotracheally intubated to our department for ultimate evaluation. His past history was remarkable for a diphtherial tracheomalacia at the age of 2 years, requiring a cervical tracheotomy and long-term intubation; a postintubation subglottic stenosis managed with a Rethi tracheoplasty ${ }^{3}$ in 2000 complicated with a dislocation of the transferred cartilage, requiring endoscopic removal; and a subglottic restenosis treated with the endoluminal placement of a flexible metal stent (Strecker, Boston Scientific Corp, Natick, Mass) in June 2002. Three months later, the patient presented again with severe dyspnea. Because bronchoscopy showed trans-stent obstructive granulations, an endobronchial debridement (core out) was made, and a silicone stent (Dumon; Bryan Corp, Woburn, Mass) was placed over the first one. Six months later, the patient was transferred to the emergency department because of severe inspiratory stridor and dyspnea, where rigid bronchoscopy revealed granulations at the ends of the Dumon stent. The granulations were removed endoscopically, and an antiobstructive therapy, broad-spectrum antibiotics, and high-doses steroids were used as treatment. However, the growth of the granulation tissue continued, and the time intervals between secretion retention, inflammation symptoms, respiratory decompensation, and endoscopic core out became steadily but progressively shorter. After a further emergency core out in February 2004, the patient experienced a

From the Department of Thoracic and Vascular Surgery, ${ }^{a}$ Heidehaus Hospital, Hannover Medical School, Hannover, Germany, and the Departments of Anaesthesiology and Intensive Care, ${ }^{\mathrm{b}}$ Helios Klinikum Berlin-Buch, Charité, Berlin, Germany.

Received for publication Oct 19, 2004; revisions received Nov 17, 2004; accepted for publication Dec 8, 2004.

Address for reprints: Paolo Macchiarini, MD, PhD, Department of General Thoracic Surgery, Hospital Clinic, University of Barcelona c/Villarroel 170, E-08036 Spain (E-mail: pmacchiarini@ compuserve.com).

J Thorac Cardiovasc Surg 2005;130:223-4

$0022-5223 / \$ 30.00$

Copyright $\odot 2005$ by The American Association for Thoracic Surgery doi:10.1016/j.jtcvs.2004.11.038

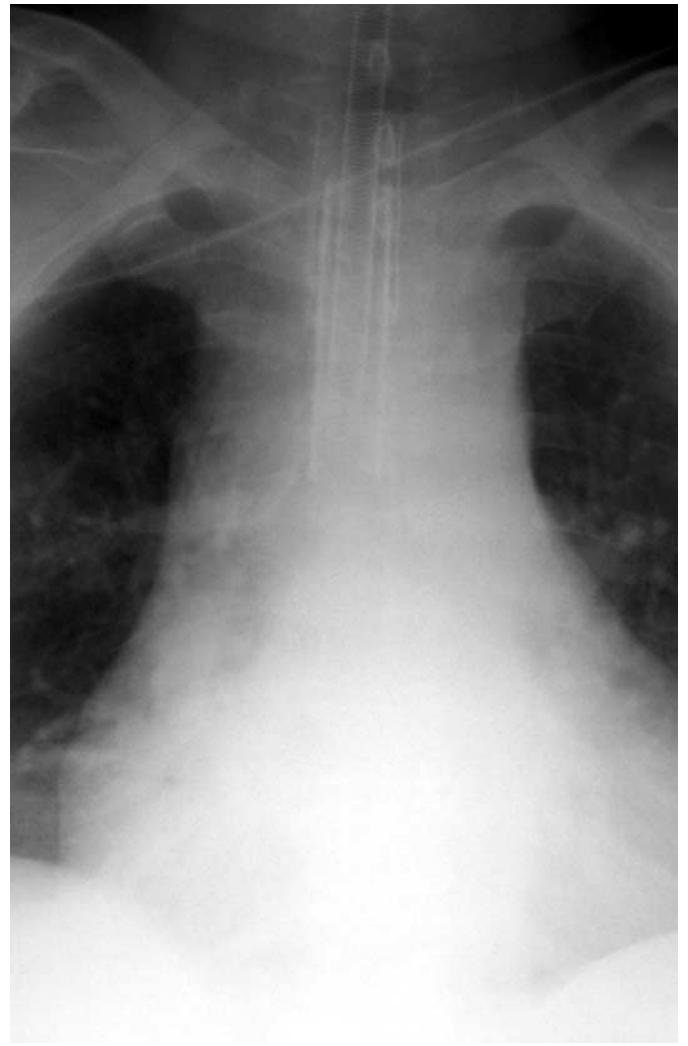

Figure 1. Preoperative chest radiograph showing the metal stent in the proximal trachea, the silicone stent migrated distally to the supracarinal region, and a flexible endotracheal tube placed through the previous stents, ensuring the patient's ventilation.

global respiratory insufficiency requiring bronchoscopically guided nasal and trans-stental intubation and mechanical ventilation.

The patient was then transferred to our intensive care unit incompletely sedated but mechanically ventilated and with increased infection parameters. A chest radiograph showed a migration of the Dumont stent in the distal trachea (Figure 1). Examination with a rigid bronchoscope showed a circumferential and 3 -cm-long subglottic stenosis, the incorporation of the almost uncoated wire stent into the entire cervical trachea mucosa, an edematous mucosa of the residual intrathoracic portion of the trachea, the Dumon stent dislocation, and massive and inspissated secretions arising from the left lung. Endobronchial bacteriologic analyses were made, and the stent was removed. Because the global length of the trachea allowed a resection and a primary reconstruction, the patient was kept mechanically ventilated with 


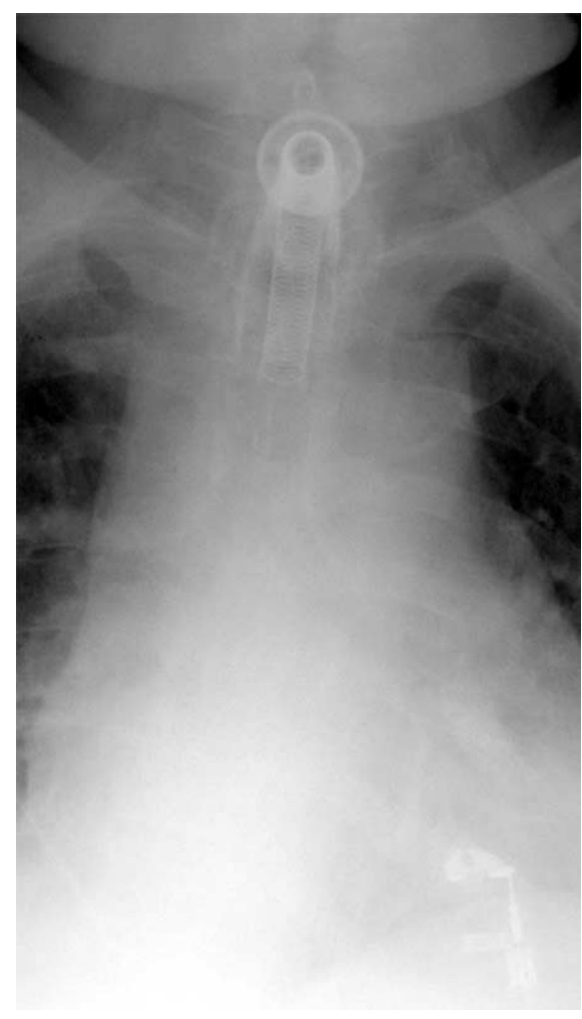

Figure 2. Postoperative (day 1) chest radiograph showing the decompressing tracheal cannula and the membranous wall remnants of the expandable metallic stent.

the original nasotracheal tube, and the operation was delayed until the patient was awake and conscious and all infections and inflammatory abnormalities subsided. A redo median cervicotomy with a subglottic resection and primary reconstruction ${ }^{4}$ associated with an extended linear cervical tracheostomy to remove as much as possible of the uncoated stent, except at the level of the membranous portion to avoid a tracheoesophageal fistula, was then performed; a flexible extra-long tracheal cannula 2 cartilage rings below the anastomosis was also placed to serve as an endotracheal tutor and to facilitate respiratory weaning (Figure 2).

\section{Results}

Extubation with spontaneous breathing was possible within 7 days, and admission to outpatient rehabilitation was possible within a further 4 days. Clinical examinations, follow-up radiographic examination, lung function tests, and repeated bronchoscopies showed no voice or other abnormalities and complete restoration of the airway mucosa 6 months later.

\section{Discussion}

Because airway stenting has its pros and cons ${ }^{1}$ and because the preference for stents over surgical repair in the absence of true contraindications is not supported by evidence, ${ }^{2}$ patients should be referred upfront in a specialized tertiary center. The case presented here provides further evidence that on one site a simple subglottic resection and reconstruction ${ }^{4}$ results in a better outcome over the Rethi operation ${ }^{3}$ for postintubation subglottic lesions and that the exhaustive enthusiasm toward endoluminal stents can sometimes be life-threatening. Whether the subglottic lesion was the result of a complete failure of the Rethi procedure or partly aggravated by the granulations that developed at the proximal end of the Strecker stent near the conus elasticus of the subglottic larynx remains to be answered. However, and in contrast to most patients, ${ }^{2}$ we were fortunate that the subglottic lesion was still resectable, even after the via cruces of this patient, adding weight to Grillo's frustration on the unfortunate current tendency of pulmonologists and even some surgeons, both otolaryngologic and thoracic, to treat surgically resectable stenoses with stents.

\section{Conclusions}

The liberal use of stents for benign tracheal disease, in which simple surgical excision usually produces definitive cure in most patients, ${ }^{5}$ should be severely disapproved because it can produce life-threatening and uncorrectable complications.

\section{References}

1. Wood DE. Tracheal and bronchial stenting. In: Grillo HC, editor. Surgery of the trachea and bronchi. London, United Kingdom: BC Decker Inc; 2004. p. 763-90.

2. Gaissert HA, Grillo $\mathrm{HC}$, Wright $\mathrm{CD}$, et al. Complication of benign tracheobronchial strictures by self-expanding metal stents. $J$ Thorac Cardiovasc Surg. 2003;126:744-7.

3. Rethi A. An operation for cicatricial stenosis of the larynx. J Laryngol Otol. 1956;70:300-5.

4. Macchiarini P, Verrhoye JP, Chapelier A, Fadel E, Dartevelle P. Partial cricoidectomy with primary thyrotracheal anastomosis for postintubation subglottic lesions. J Thorac Cardiovasc Surg. 2001;121:68-76.

5. Grillo HC. Stent and sense. Ann Thorac Surg. 2000;70:1142. 